\title{
EFFECTS OF STRUCTURE AND HYDRODYNAMICS ON THE SOOTING BEHAVIOR OF SPHERICAL MICROGRAVITY DIFFUSION FLAMES
}

\author{
P. B. SUNDERLAND \\ NCMR, NASA Glenn Research Center, Cleveland \\ R. L. AXELBAUM \\ Washington University, St. Louis \\ D. L. URBAN \\ NASA Glenn Research Center, Cleveland \\ Submitted to: \\ $28^{\text {th }}$ Symposium on Combustion \\ Suggested Colloquium: \\ Soot, PAH and Air Toxins \\ Presentation Preference: \\ Oral
}

Word Count:

Body: 2735

Figures: $1-400,2-400,3-1200,4-200$

Total: 4935

Date Submitted:

December 14, 1999

Address Correspondence:

Richard L. Axelbaum

Department of Mechanical Engineering

Washington University

Campus Box 1185

One Brookings Drive

St. Louis, MO 63130, USA

Tel: (314) 935-7560

Fax: (314) 935-4014

rla@mecf.wustl.edu 


\title{
EFFECTS OF STRUCTURE AND HYDRODYNAMICS ON THE SOOTING BEHAVIOR OF SPHERICAL MICROGRAVITY DIFFUSION FLAMES
}

\author{
P. B. SUNDERLAND, R. L. AXELBAUM, and D. L. URBAN
}

\begin{abstract}
We have examined the sooting behavior of spherical microgravity diffusion flames burning ethylene at atmospheric pressure in the NASA Glenn 2.2-second drop tower. In a novel application of microgravity, spherical flames allowed convection across the flame to be either from fuel to oxidizer or from oxidizer to fuel. Thus, microgravity flames are uniquely capable of allowing independent variation of convection direction across the flame and stoichiometric mixture fraction, $Z_{\mathrm{st}}$. This allowed us to determine the dominant mechanism responsible for the phenomenon of permanently-blue diffusion flames -- flames that remain blue as strain rate approaches zero. Stoichiometric mixture fraction was varied by changing inert concentrations such that adiabatic flame temperature did not change. At low and high $Z_{\text {st }}$ nitrogen was supplied with the oxidizer and the fuel, respectively. For the present flames, structure $\left(Z_{s t}\right)$ was found to have a profound effect on soot production. Soot-free conditions were observed at high $Z_{\mathrm{st}}\left(Z_{\mathrm{st}}=\right.$ $0.78)$ and sooting conditions were observed at low $Z_{\mathrm{st}}\left(Z_{\mathrm{st}}=0.064\right)$ regardless of the direction of convection. Convection direction was found to have a lesser impact on soot inception, with formation being suppressed when convection at the flame sheet was directed towards the oxidizer.
\end{abstract}

This is a preprint or reprint of a paper intended for presentation at a conference. This is a preprint or reprint of a paper intended for presentation at a conlerence. Because changes may be made before formal publication, this is made avallable with the author.
understanding that it will not be cited or reproduced without the permission of the aut 


\section{Introduction}

The unique properties of spherical diffusion flames have attracted much attention. Their structure has been considered theoretically by Buckmaster and Ludford [1], Williams [2] and Mills and Matalon [3]. Observations of these flames typically have involved droplet combustion in microgravity [4-6], although flames supported by porous spheres in microgravity $[7,8]$ and in normal gravity [9] have been considered as well. Since spherical diffusion flames are onedimensional and strain-free they hold great utility for studies of soot formation.

Recent experimental, numerical and analytical work has shown that stoichiometric mixture fraction [2] can have a profound effect on soot formation in diffusion flames [10-16]. This effect appears even at constant adiabatic flame temperature $\left(T_{\mathrm{ad}}\right)$, as demonstrated by Du and Axelbaum $[10,11]$. For example, a fuel mixture containing 1 mole of ethylene and 11.28 moles of nitrogen burning in pure oxygen $\left(Z_{\mathrm{st}}=0.78\right)$ has the same adiabatic flame temperature $(2370 \mathrm{~K})$ as that of pure ethylene burning in air $\left(Z_{\mathrm{st}}=0.064\right)$. An important finding was that at sufficiently high $Z_{\mathrm{st}}$, flames remain blue when the strain rate approaches zero in counterflow flames, or as flame height and residence time approach infinity in coflowing flames. Lin and Faeth [13] coined the term permanently blue to describe such flames.

Two theories have been proposed to explain the appearance of permanently-blue flames at high $Z_{\mathrm{st}}$. They are based on (1) hydrodynamics [13-16] and (2) flame structure [10,12]. Fig. 1 illustrates the hydrodynamic effect for counterflow flames. When fuel and oxidizer are chosen such that $Z_{\mathrm{st}}<0.5$ (Fig. 1a) the flame lies on the oxidizer side of the stagnation plane and thus the streamlines at the flame are directed towards the fuel. Newly formed soot is convected into richer regions, favoring soot growth over oxidation. On the other hand, when $Z_{s t}>0.5$ (Fig. 1b) the flame is on the fuel side and convection at the flame is towards the oxidizer. Thus, in counterflow flames, hydrodynamics drives the soot towards the oxidizer, thereby retarding soot formation. 
$\mathrm{Du}$ and Axelbaum (Ref. 10 comment and reply) proposed that while the direction of convection can impact soot growth and oxidation, it is instead the absence of inception that dictates permanently-blue conditions. Growth and oxidation depend on the existence of soot particles, whereas soot-particle inception arises from gas-phase reactions. While particles have relatively small diffusion velocities and follow streamlines, gaseous species are not constrained in this way. Thus inception cannot depend strongly on flow direction. For example, there is no abrupt change in gas-phase behavior when a flame moves across the stagnation plane [11]. The flame is a diffusive-convective system and this balance allows for changes in convective direction without substantial changes in flame response. Furthermore, since the soot-inception zone has a finite thickness, it is possible to produce soot in counterflow flames when $Z_{\mathrm{st}}>0.5$ even though convection drives particles into the oxidizer [10].

This structural explanation for permanently-blue flames is illustrated in Fig. 2. The fuel, oxygen and temperature distributions in $Z$ space are depicted for the standard ethylene/air flame $\left(Z_{\mathrm{st}}=\right.$ $0.064)$ in Fig. $2 a$, and for the diluted ethylene/oxygen flame $\left(Z_{\mathrm{st}}=0.78\right)$ in Fig. $2 \mathrm{~b}$. The flame sheet solution is shown, but dashed lines delineate the high-temperature boundaries of a broadened reaction zone. The hatched (?) region identifies the relevant soot zone on the fuel side of the flame sheet. As described in Ref. 10, flames with large $Z_{\text {st }}$ have lower fuel concentrations and higher oxygen concentrations in the soot zone. They also have a shift in the $\mathrm{OH}$ profile towards the fuel side of the flame. Since the presence of $\mathrm{O}_{2}$ (and to a lesser extent $\mathrm{OH}$ ) retards precursor growth [17], this shift can dramatically reduce soot inception by narrowing the sootinception zone. From this perspective, permanently-blue conditions are realized when significant oxidizing species are on the fuel side in the region where temperatures are above the threshold temperature for soot inception, $1250 \mathrm{~K}$ at moderate pressures [18]. For such flames, in regions where temperatures are high enough to produce soot, there is sufficient oxidizer to consume the 
soot precursors. Consumption overcomes production and, in this respect, the soot formation region at high $Z_{\mathrm{st}}$ resembles that of soot-free premixed flames.

Flames considered in past studies, which involved counterflow and gas-jet configurations, did not allow independent variation of flame structure and convection direction. It was not possible to assess the relative contributions of hydrodynamics and structure because both structure and hydrodynamics suppress soot formation at high $Z_{\mathrm{st}}$ in normal-gravity diffusion flames. As described below, spherical diffusion flames allow both properties to be varied independently. This attribute motivated this study. We independently varied the direction of convection across the flame sheet by interchanging the injected and ambient gases. We altered structure $\left(Z_{\mathrm{st}}\right)$ by exchanging inert between the oxidizer and the fuel with a procedure that maintains constant adiabatic flame temperature [10].

Thus motivated, we established four flames: (a) ethylene issuing into air, (b) diluted ethylene issuing into oxygen, (c) air issuing into ethylene, and (d) oxygen issuing into diluted ethylene. $Z_{\text {st }}$ is 0.064 in Flames (a) and (c), and 0.78 in Flames (b) and (d). The convection direction is from fuel to oxidizer in Flames (a) and (b) and from oxidizer to fuel in Flames (c) and (d). Under the assumption of equal diffusivities of all species and heat, the stoichiometric contours of these flames have identical nitrogen concentrations and adiabatic temperatures.

\section{Experimental}

The experiments were conducted in the NASA Glenn 2.2-second drop tower using a generalpurpose combustion rig. The rig consists of a windowed pressure vessel supported by a fueldelivery system, an ignitor, a color CCD camera, a microprocessor controller and lead-acid batteries. The burner is a $6.4 \mathrm{~mm}$ diameter porous sphere consisting of sintered 10 micron stainless steel particles. The sphere was supported and fed by a $1.6 \mathrm{~mm}$ stainless steel tube attached with epoxy. The sphere was positioned at the center of the cylindrical chamber, whose 
diameter, length and volume were $25 \mathrm{~cm}, 53 \mathrm{~cm}$ and 27 liters, respectively. All tests were conducted in quiescent ambient gas at $98 \mathrm{kPa}$.

The present tests employed the following gases: ethylene, oxygen, synthetic air (21\% oxygen by volume in nitrogen) and diluted ethylene (8.14\% ethylene by volume in nitrogen). Purities of the nitrogen and oxygen were $99.999 \%$ while that for ethylene was $99.9 \%$. Nitrogen mixtures were purchased, having been prepared by gravimetric mixing to within $0.02 \%$ of the reported compositions. The burner feed gas was stored at $800 \mathrm{kPa}$ in a $75 \mathrm{ml}$ bottle aboard the rig and was delivered via a pressure regulator, a solenoid valve, a fine-needle valve, a mass-flow meter, and a second solenoid valve. Burner flow rates were established prior to ignition with the massflow meter, which was calibrated for each gas using a bubble meter. Uncertainties in the flowrates (at the 95\% confidence level) are estimated at 5\%. Prior to each test, two purges of the chamber were performed by evacuating the chamber to $3 \mathrm{kPa}$ and filling with ambient gas.

Microgravity laminar flames are sensitive to hydrodynamic disturbances such as those caused by ignition prior to entry into microgravity, retracting ignitors and ignition deflagrations. To minimize these disturbances, the flames were ignited immediately after release into microgravity using a spring-loaded hot wire (Nichrome with a length of $12 \mathrm{~mm}$ and a diameter of $0.36 \mathrm{~mm}$ ) mounted in tension near the sphere-tube seam. An ignitor was energized at $28 \mathrm{VDC}$, whereby it quickly glowed and ruptured and both ends retracted with minimal wakes. The serial pair of solenoid valves facilitated smooth ignition via optimization of the initial gas discharge.

The flames were imaged through the chamber window (BK7) using a color CCD camera. A 16 $\mathrm{mm}$ fixed-iris lens was used, with apertures (f 1.4-6) chosen according to flame luminosity. Video signals were carried via fiber-optic cable to a stationary color S-VHS video recorder: Digitized images were subsequently obtained from the tapes using a framegrabber. Spatial resolution in the video images was $0.3 \mathrm{~mm}$. Soot formation in diffusion flames commences at 
about $1250 \mathrm{~K}$ [18], at which temperature soot emits visible light. Thus, diffusion flames that create soot necessarily emit yellow luminosity, and experiments have shown that the onset of yellow emissions is an effective means of determining soot inception limits in hydrocarbon diffusion flames [19]. Testing in normal gravity has confirmed our video system to be sensitive to the presence of even trace quantities of soot in flames.

\section{Results and Discussion}

Figure 3 shows color images, captured just prior to drop termination, of representative flames for the four conditions considered. Each flame has an ethylene consumption rate of $1.5 \mathrm{mg} / \mathrm{s}$ and an adiabatic flame temperature of $2370 \mathrm{~K}$. At least ten flames at each condition were observed in order to confirm repeatability. Additionally, flame size was varied to ensure the results were not affected by heat loss to the burner. Fig. 3a shows a flame of ethylene burning in air. This flame has a yellow interior surrounded by a well-defined blue sheet. Fig. $3 \mathrm{~b}$ involves diluted ethylene issuing into ambient oxygen, which yields a bright blue flame. Fig. $3 \mathrm{c}$ shows a flame of air issuing into ethylene, which is yellow and brighter than the others. Finally, Fig. 3d shows a flame of oxygen issuing into diluted ethylene, which has a dim blue interior surrounded by a bright blue sheet. Flames of Figs. 3b-d had little color variation throughout the 2-second tests while those of Fig. 3a displayed a slowly decreasing yellow luminosity.

The images reveal that the sootiest flame is obtained for air injecting into ethylene (Fig. 3c). This is expected since both flame structure (small $Z_{\mathrm{st}}$ ) and convection direction (towards fuel) promote soot formation. Conversely, one would expect the least sooty flame to be that of Fig. 3b since it has a large $Z_{\mathrm{st}}$ and convection is into the oxidizer, both of which impede soot formation. Indeed, Fig. $3 \mathrm{~b}$ reveals a soot-free flame.

The effect of convection direction at constant $Z_{\mathrm{st}}$ is best demonstrated by comparing Figs. 3a and 3c. These flames both have $Z_{\mathrm{st}}=0.064$ but have opposite convection directions; $3 \mathrm{a}$ is towards 
the oxidizer while $3 \mathrm{~b}$ is towards the fuel. The presence of diminished yellow luminosity in Fig. $3 \mathrm{a}$ indicates that directing convection towards the oxidizer suppresses soot growth and enhances soot oxidation but does not eliminate soot formation. Figs. $3 \mathrm{~b}$ and $3 \mathrm{~d}$ also have opposite directions of convection, this time at $Z_{\text {st }}=0.78$, but a comparison of sooting tendency is not possible since both flames are soot-free.

The effect of structure is apparent when comparing Figs. $3 \mathrm{c}$ and $3 \mathrm{~d}$, where convection is directed towards the fuel for both flames. Structure has a dramatic effect on soot formation in these flames, changing a strongly luminous flame to a purely blue flame when $Z_{\mathrm{st}}$ is increased from 0.064 to 0.78 . A pure blue state is realized in Fig. 3d despite unfavorable hydrodynamics. Another, though less dramatic, demonstration of reduced soot formation at high $Z_{\text {st }}$ appears in Figs. $3 \mathrm{a}$ and $3 \mathrm{~b}$. These results attest to the importance of structure and the existence of soot-free diffusion flames at high $Z_{\text {st }}$ even when the flames have high flame temperatures and low strain rates.

This method of varying convection direction also changes flame curvature. For example, the curvature in Figs. $3 a$ and $3 b$ is of opposite sign to that of Figs. $3 c$ and $3 d$. The present flames indicate curvature is not responsible for soot-free conditions because Figs. $3 b$ and $3 d$ have opposite curvature and neither produces soot. Curvature may contribute to the differences in soot concentration observed between Figs. $3 a$ and $c$ but these differences are easily explained by convection alone, as described above. Finally, as mentioned above we observed little or no variation of sooting behavior for flames of different diameters (thus different curvatures).

Unfortunately, the present results are limited by the inherent unsteadiness of 2.2 -second tests. The temporal variation of luminous flame diameter for the four flames of Fig. 3 is shown in Fig. 4. Diameters were determined by averaging the longest chord through a flame and its perpendicular chord. Time is defined to be zero upon ignition. As Fig. 4 shows, upon ignition a 
premixed deflagration propagates outward quickly and then the flame contracts into nonpremixed conditions From about $200-400 \mathrm{~ms}$ after ignition until drop termination, the flames grow monotonically but do not reach steady diameters; this transient behavior is especially evident where nitrogen is supplied in the ambient gas. Microgravity tests in gas-jet flames indicate that although quasi-steady flame shapes appear within a few seconds $[20,21]$, steady sooting behavior requires test times exceeding those of ground-based facilities [21]. Furthermore, in the present brief tests, thermophoresis may trap within the flames some soot formed during ignition. Longer microgravity test times are required, and are being pursued.

\section{Conclusions}

Four configurations of spherical microgravity diffusion flames were observed in the NASA Glenn 2.2-second drop tower. The conditions are uniquely suited to studying permanently-blue flames since they allow independent variation of stoichiometric mixture fraction and convection direction. Flames with $Z_{\mathrm{st}}=0.78$ were soot-free and flames with $Z_{\mathrm{st}}=0.064$ appeared yellow regardless of convection direction. For the flames with low $Z_{\mathrm{st}}$, less soot was evident when convection was towards the oxidizer, but pure blue conditions were not realized. We thus surmise that permanently-blue flames owe their existence more to flame structure (inert orientation) than to convection direction.

An important ancillary result of this work is the demonstration of a unique application of microgravity that should have applications beyond this study. That is, the direction of convection across the flame can be reversed for purely one-dimensional diffusion flames. This is not possible in normal gravity. Thus, microgravity affords a new level of control and a unique tool for studying diffusion flames. 
Acknowledgments

This work was supported by NASA Grants NCC3-697 and NAG3-1910 (RLA) and by the

National Research Council (PBS). The assistance of S. A. Gokoglu, C. B. Lundquist, J. E.

Pierce, and H. D. Ross is duly appreciated.

\section{REFERENCES}

1. Buckmaster, J. D. and Ludford, G. S. S., Theory of Laminar Flames, Cambridge University Press, Cambridge, 1982, pp. 95-110.

2. Williams, F. A., Combustion Theory, Benjamin/Cummings, Menlo Park, 1985, pp. 52 and 75.

3. Mills, K. and Matalon, M., Comb. Sci. Tech. 129:295-319 (1997).

4. Avedesian, C. T., "Emulsion Droplet Combustion in Microgravity: Water/Heptane Emulsions," Proceedings of the $4^{\text {th }}$ International Microgravity Combustion Workshop, NASA Conference Publication 10194, p. 467-472 (1997).

5. Choi, M. Y. and Lee, K. -O., Twenty-Sixth Symposium (International) on Combustion, The Combustion Institute, Pittsburgh, PA, 1996, pp. 1243-1249.

6. Nayagam, V., Haggard, J. B. Jr., Colantonio, R. O., Marchese, A. J., Dryer, F. L., Zhang, B. L., and Williams, F. A., AIAA J. 36:1369-1378 (1998).

7. Atreya, A., Agrawal, S., Shamim, T., Pickett, K., Sacksteder, K. R., and Baum, H. R., "Radiant Extinction of Gaseous Diffusion Flames," Proceedings of the $3^{\text {rd }}$ International Microgravity Combustion Workshop, NASA Conference Publication 10174, p. 319-325 (1995).

8. Law, C. K., Sung, C. J., and Zhu, D. L., "Studies of Flame Structure in Microgravity," Proceedings of the $4^{\text {th }}$ International Microgravity Combustion Workshop, NASA Conference Publication 10194, pp. 69-74 (1997).

9. Sung, C. J., Zhu, D. L., and Law, C. K., Twenty-Seventh Symposium (International) on Combustion, The Combustion Institute, Pittsburgh, PA, 1998, pp. 2559-2566.

10. Du, J . and Axelbaum, R. L., Combust. Flame 100:367-375 (1995).

11. Du, J., and Axelbaum, R. L., Twenty-Sixth Symposium (International) on Combustion, The Combustion Institute, Pittsburgh, PA, 1996 pp. 1137-1142.

12. Chao, B. H., Liu, S. and Axelbaum, R. L., Comb. Sci. Tech 138:105-135 (1998).

13. Lin, K. -C. and Faeth, G. M., J. Prop. Power 12:691-698 (1996).

14. Lin, K. -C. and Faeth, G. M., J. Prop. Power 12:10-17 (1996).

15. Lin, K. -C. and Faeth, G. M., Combust. Flame 115:468-480 (1998).

16. Sugiyama, G., Twenty-Fifth Symposium (International) on Combustion, The Combustion Institute, Pittsburgh, PA, 1994, pp. 601-608.

17. Markatou, P., Wang, H., Frenklach, M., Comb. Flame 93:467-? (1993).

18. Sunderland, P. B., Köylü, Ü. Ö., and Faeth, G. M., Combust. Flame 100:310-322 (1995).

19. Du, D. X., Axelbaum, R. L., and Law, C. K., Twenty-Second Symposium (International) on Combustion, The Combustion Institute, Pittsburgh, PA, 1988, pp. 387-394. 
20. Sunderland, P. B., Mendelson, B. J., Yuan, Z. -G., and Urban, D. L., Combust. Flame 116:376-386 (1999).

21. Urban, D. L., Yuan, Z. -G, Sunderland, P. B., Linteris, G. T., Voss, J. E., Lin, K. -C., Dai, Z., Sun, K., and Faeth, G. M., AIAA J. 36:1346-1360 (1998). 


\section{FIGURE CAPTIONS}

FIG. 1. Schematic representation of counterflow flames with (a) $Z_{\mathrm{st}}<0.5$ such that the flame is on the oxidizer side of the stagnation plane and the flow is from the soot inception region to the fuel source and (b) $Z_{\mathrm{st}}>0.5$ such that the flame is on the fuel side of the stagnation plane and the flow is from the soot inception region to the oxidizer source.

FIG. 2. Representation of normalized temperature $\left(T / T_{a d}\right)$ and fuel and oxidizer mass fractions $\left(Y_{i}\right)$ versus mixture fraction $(Z)$ for diffusion flames with (a) $Z_{s t}=0.064$ and (b) $Z_{s t}=0.78$. The dashed lines identify a high temperature zone for discussion purposes. Reproduced from $\mathrm{Du}$ and Axelbaum [10].

FIG. 3. Color images of representative flames at the end of the 2.2 second drop: (a) ethylene $(1.51 \mathrm{mg} / \mathrm{s})$ issuing into air, $Z_{\mathrm{st}}=0.064, \mathrm{f} 1.4$; (b) diluted ethylene $(19 \mathrm{mg} / \mathrm{s})$ issuing into oxygen, $Z_{\mathrm{st}}=0.78$, f1.4; (c) air $(22 \mathrm{mg} / \mathrm{s})$ issuing into ethylene, $Z_{\mathrm{st}}=0.064, \mathrm{f6}$; (d) oxygen $(5.2 \mathrm{mg} / \mathrm{s})$ issuing into diluted ethylene, $Z_{\mathrm{st}}=0.78, \mathrm{f} 6$. The scale is revealed by the $6.4 \mathrm{~mm}$ spherical burner. The ethylene consumption rate is $1.51 \mathrm{mg} / \mathrm{s}$ in all cases.

FIG. 4. Variation of flame luminous diameter, $d$, with time, $t$, for the flames of Fig. 3. 


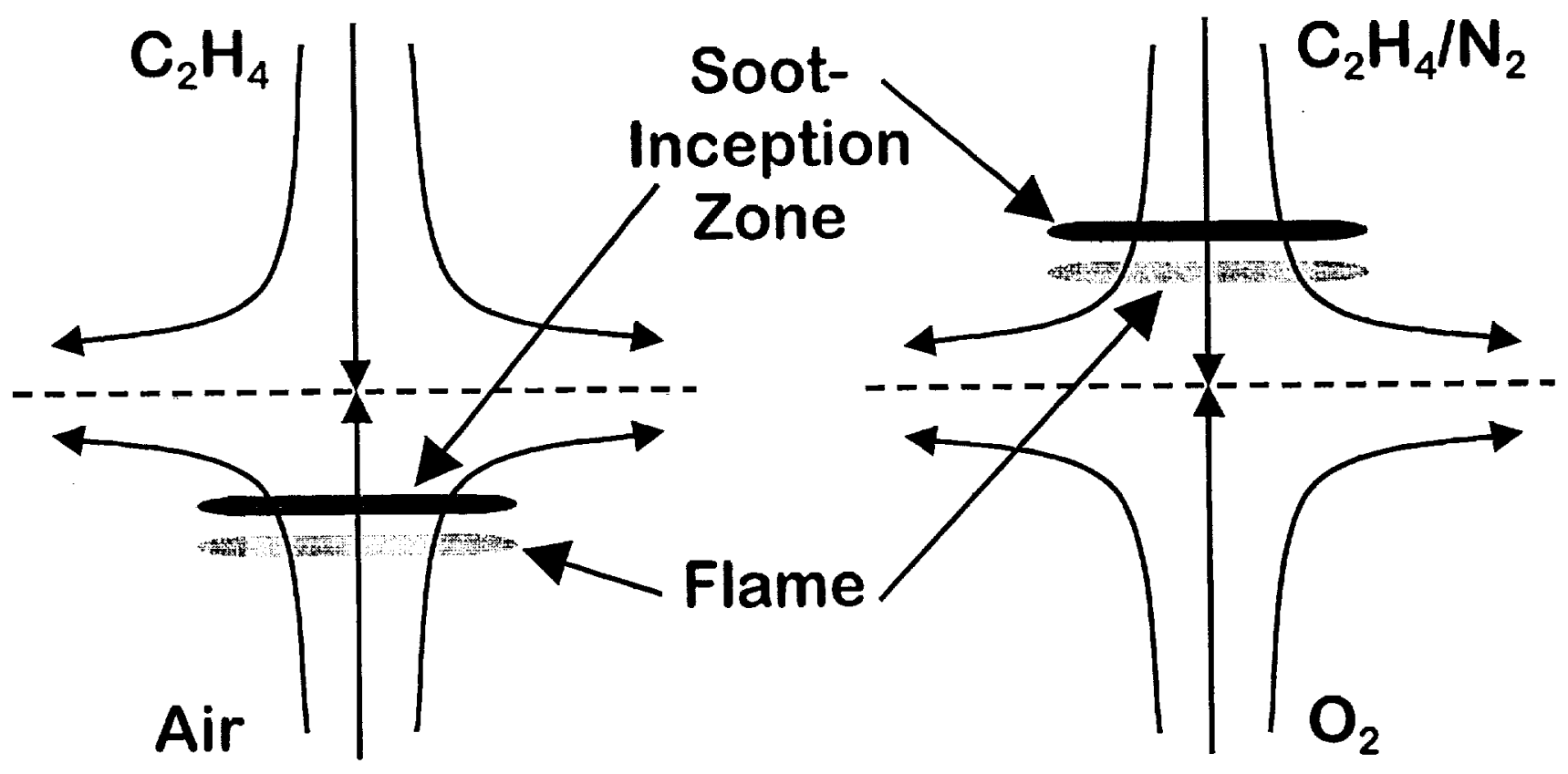

(a)

(b) 


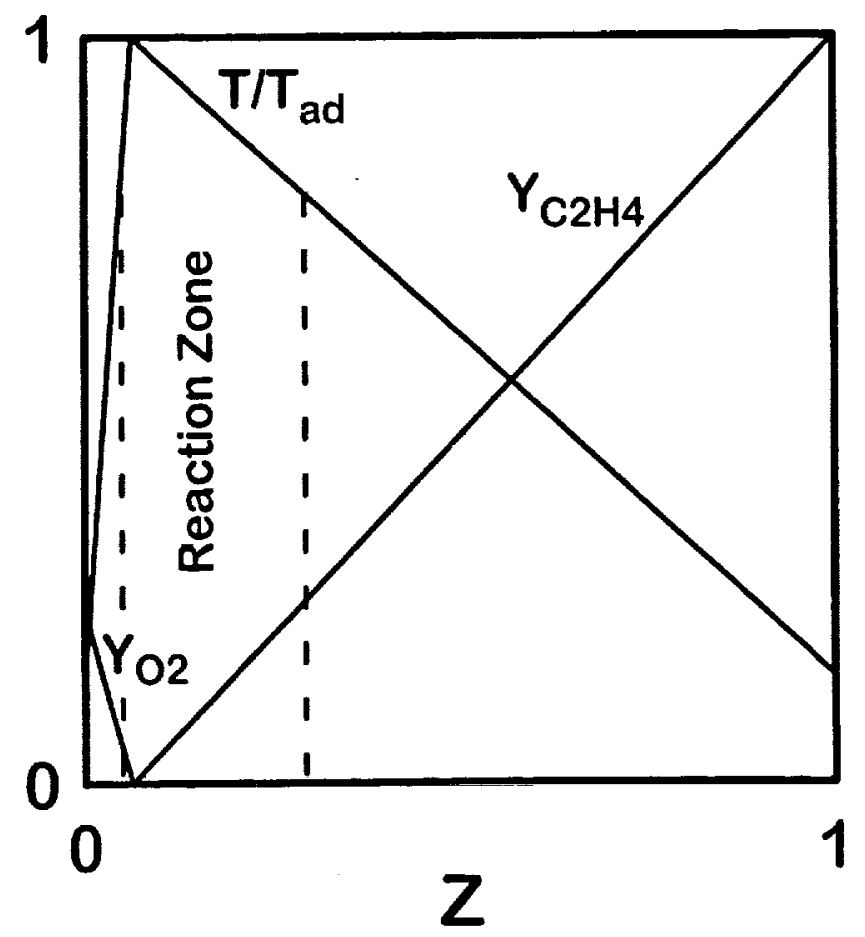

(a)

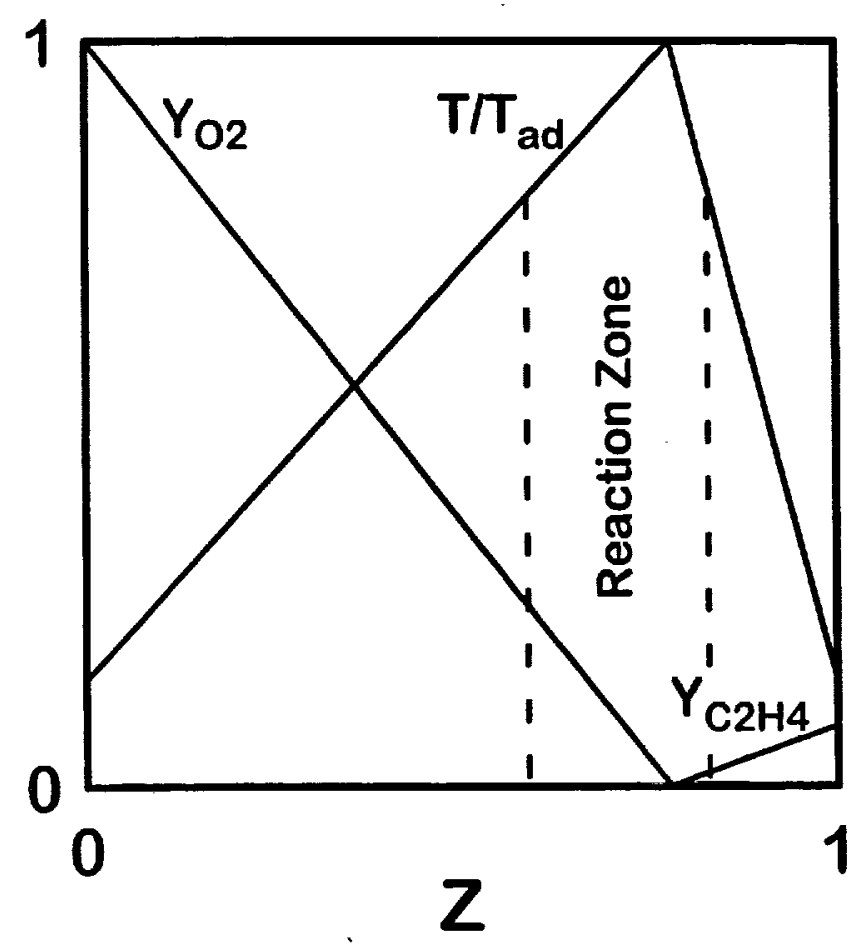

(b) 


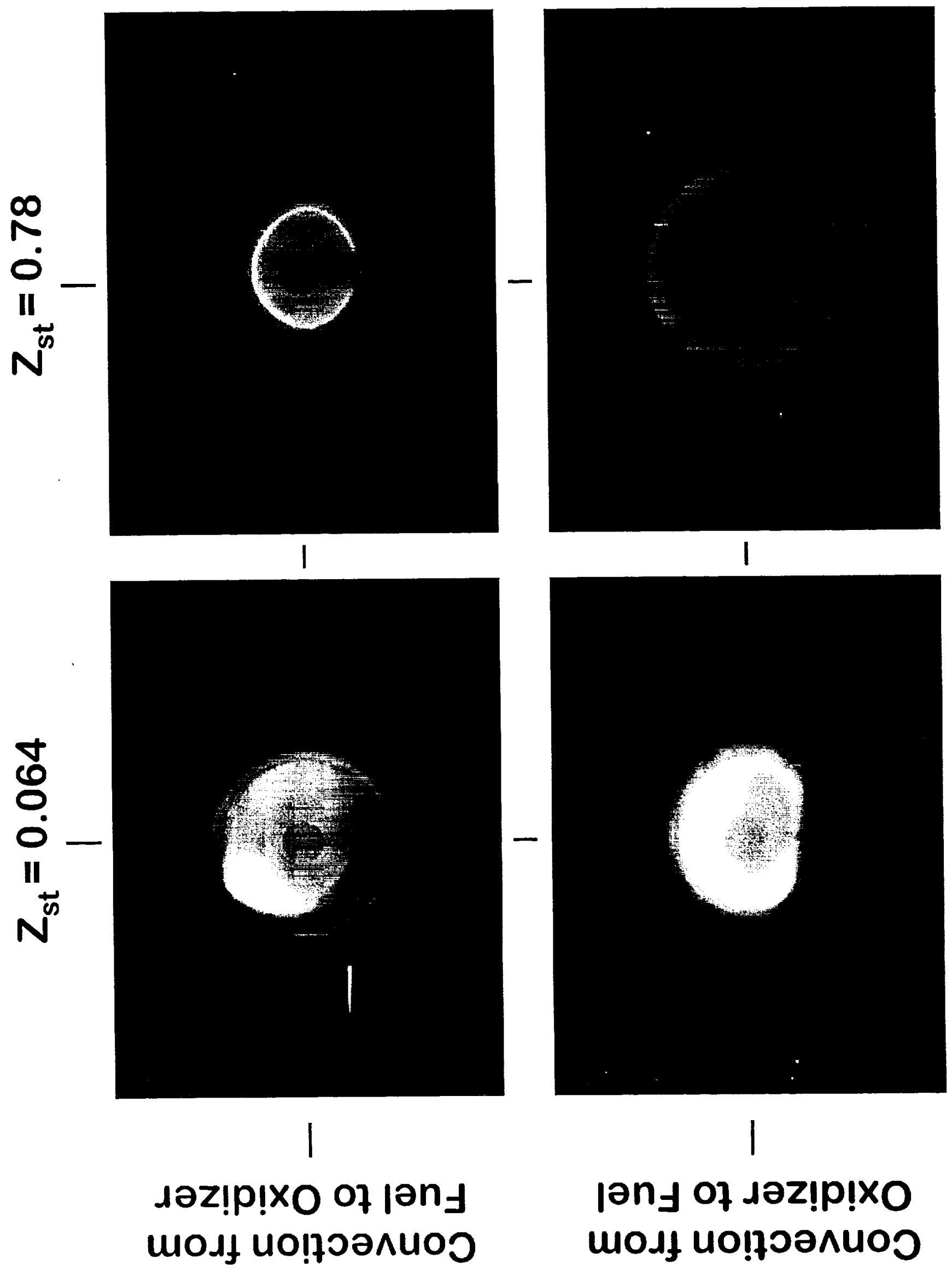




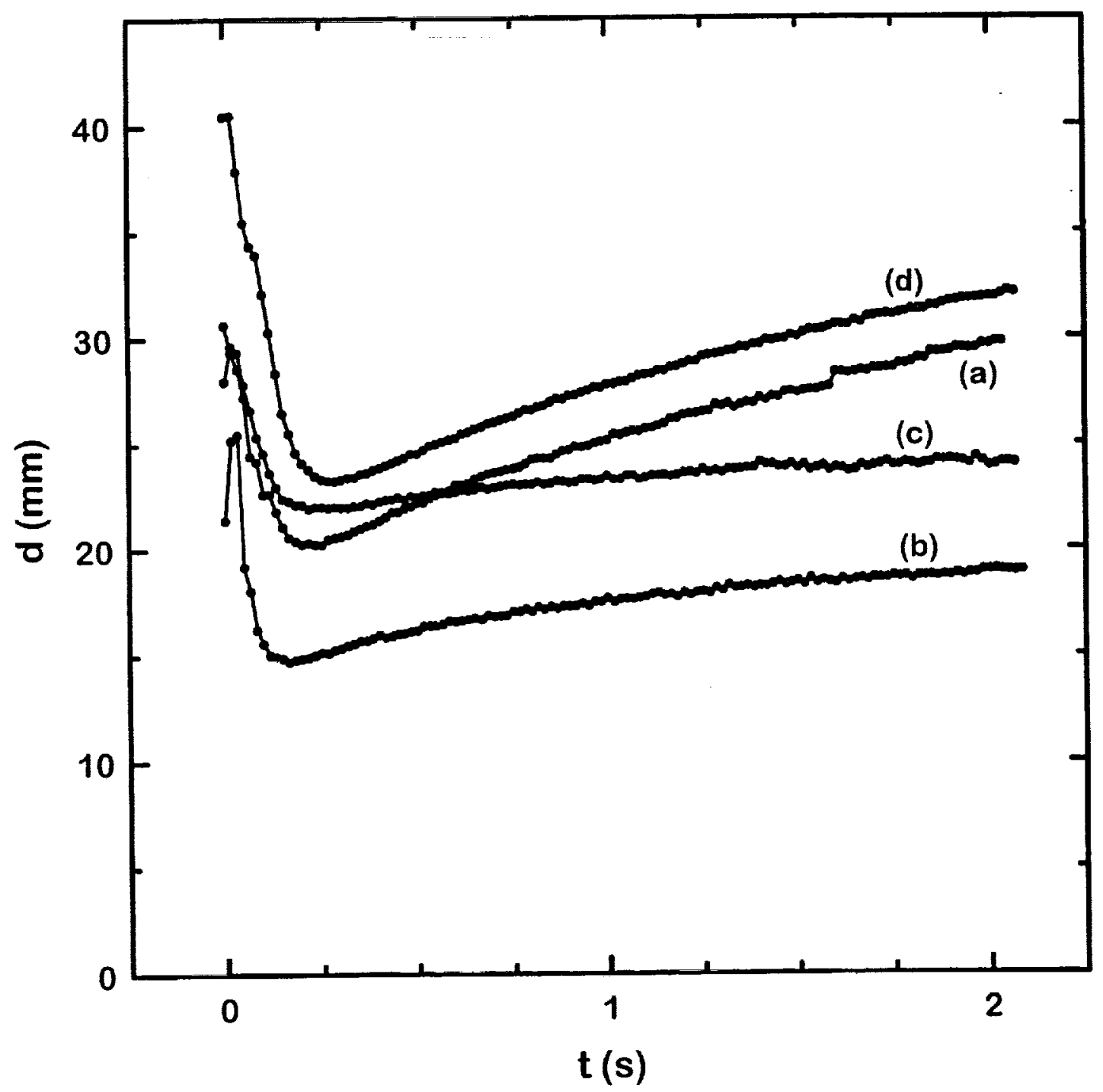

